\title{
PRECEITOS PARA BEM VIVER: UM ESTUDO SOBRE MANUAIS DE CIVILIDADE E ETIQUETA NA DÉCADA DE 1950
}

\author{
PRECEPTS TO LIVE WELL: \\ A STUDY ON CIVILITY AND ETIQUETTE \\ MANUALS IN THE 1950S
}

\section{PRECEPTOS PARA UNA BUENA VIDA: UN ESTUDIO SOBRE LOS MANUALES DE CIVILIDAD Y ETIQUETA EN LA DÉCADA DE 1950}

\author{
Maria Teresa Santos Cunha ${ }^{\mathrm{I}}$ \\ Márcia Regina dos Santos ${ }^{\mathrm{I}}$ \\ IUniversidade do Estado de Santa Catarina (UDESC), \\ FLORIANÓPOLIS/SC - BRASIL.
}

\begin{abstract}
REsumo O período posterior às guerras mundiais demandou a reinvenção das convivências, do sentimento de pertença e das formas de distinção. O presente artigo discutirá as leituras de formação, mais precisamente, manuais de etiqueta e boas maneiras produzidos para contribuírem no processo de reabilitação dos modos entendidos como civilizados, no sentido de compreender as concepções do que é civilizado em cada tempo, as formas mobilizadas para internalizar os hábitos, os tipos de conteúdos divulgados e quais eram os ensinamentos propostos na literatura sobre boas maneiras. Como corpo documental, foram selecionados dois manuais de boas maneiras produzidos na década de 1950, editados e comercializados no Brasil, intitulados Aprenda boas maneiras, da autora Dora Maria (1958) e Boas maneiras, da autora Carmen D'Ávila (1958). A análise dos documentos sinalizou que a formação proposta nos dois manuais se constrói a partir de lugares diferentes que convergem para uma mesma organização. As considerações elaboradas a partir das discussões de Norbert Elias sobre o tema, a abordagem de alguns conteúdos e a análise da materialidade permitiram evidenciar a continuidade dessa demanda por formação e o potencial de alcance das prescrições.
\end{abstract}

Palavras-chave: Manuais de civilidade; Etiqueta; Norbert Elias. 
Abstract The post-World Wars period has demanded the reinvention of the coexistences, of the feeling of belonging and of the ways of distinction. The following article will discuss the readings for education, more precisely, the etiquette manuals and good manners produced to contribute in the process of rehabilitation of the behavior that was seen as civilized, intending to comprehend the conceptions of what is civilized in each period of time, the ways used to internalize habits, the kinds of contents publicized and what were the teachings proposed in the literature about good manners. The manuals of good manners produced during the 1950s, edited and sold in Brazil, titled Aprenda boas maneiras, from author Dora Maria (1958), and Boas maneiras, of the author Carmen D'Ávila (1958), were chosen as documents to be examined. The analysis of the documents signalized that the formation proposed in the two manuals is built from different perspectives, that converge to the same organization. The thoughts elaborated from the discussion with Norbert Elias about this issue, the approach given to some contents and the analysis of the materiality allowed to indicate the continuity of this demand for formation and the reaching potential of the prescriptions.

Key-words: Civility Manuals; Etiquette; Norbert Elias.

Resumen El período después de las guerras mundiales ha creado condiciones para la reinvención de las coexistencias, el sentimiento de pertenencia y las formas de distinción. Este artículo tiene la intención de discutir las lecturas de formación, más precisamente, los manuales de civilidade y etiqueta y las buenas maneras producidas para contribuir al proceso de rehabilitación de los modos entendidos como civilizados, con el fin de comprender las concepciones de lo civilizado en cada momento, las formas movilizadas para internalizar los hábitos, los tipos de contenidos divulgados y cuáles fueron las enseñanzas propuestas en la literatura sobre buenas maneras. Como órgano documental se seleccionaron dos manuales de buenos modales producidos en la década de 1950, editados y comercializados en Brasil, titulados, Aprenda boas maneiras, por el autor Dora Maria (1958) y Boas maneiras, por el autor Carmen de Ávila (1958). El análisis de los documentos señaló que la formación propuesta en los dos manuales se construye desde diferentes lugares que convergen a la misma organización. Las consideraciones elaboradas a partir de la discusión con las propuestas de Norbert Elias sobre el tema, el enfoque de algunos contenidos y el análisis de la materialidad permitieron destacar la continuidad de esta demanda de formación y el potencial del alcance de las prescripciones.

Palabras Clave: Manuales de Civilidad; Etiqueta; Norbert Elias.

\section{INTRODUÇÃO}

As pressões que atuam sobre o indivíduo tendem a produzir uma transformação de toda a economia das paixões e afetos rumo a uma regulação mais contínua, estável e uniforme dos mesmos, em todas as áreas de conduta, em todos os setores de sua vida. [...] Desde o começo da mocidade, o indivíduo é treinado no autocontrole [...] que produz esse abrandamento de paixões e sentimentos (ELIAS, 1993, p. 202). 
O século XX, desde suas décadas iniciais, foi cenário de contínuas transformações sociais, políticas e culturais. Os países direta e indiretamente envolvidos nos dois conflitos mundiais, principalmente a Segunda Guerra, foram acometidos por crises sem precedentes em diversas dimensões das sociedades. Além da destruição material, as relações interpessoais e as percepções temporais foram afetadas, de tal forma, que as sensibilidades e as abstrações acerca da vida em sociedade tiveram seus contornos alterados, constituindo novos percursos no processo civilizador. Após vivenciar a violência extrema que resultou na interrupção dos projetos de futuro, o período posterior à Segunda Guerra demandou a reinvenção das convivências, do sentimento de pertença e das formas de distinção. Os elementos constitutivos da fase de reconstrução foram inúmeros e, este artigo destacará os espaços das leituras de formação, mais precisamente, manuais de etiqueta e boas maneiras produzidos para contribuírem nesse processo de reabilitação dos modos compreendidos como civilizados. Segundo estudos feitos em diálogo com Norbert Elias, esses espaços de leitura são, igualmente, locais de educação e, como tais, "são fortemente regulados pelo controle dos adultos, no sentido de garantir às gerações posteriores o aprendizado que lhes permita a inserção e civilização dentro de seu grupo social" (SARAT, 2009, p. 107). Como corpo documental, foram selecionados dois manuais de boas maneiras produzidos na década de 1950, editados e comercializados no Brasil, intitulados Aprenda boas maneiras, da autora Dora Maria (1958) e Boas maneiras, da autora Carmen D’Ávila (1958).

A década de 1950 compreende um período de reelaboração no que tange às relações e aos projetos de futuro, portanto, os dois manuais estão circunscritos pelas sensibilidades emergentes do contexto do pós-guerra. Constituídos como guias, os manuais de Maria e D'Ávila eram portadores de prescrições de comportamentos considerados adequados, visando a formar um tecido social no qual as ações individuais contribuíssem para uma estabilidade coletiva. À luz dos debates produzidos por Norbert Elias, compreende-se que,

\footnotetext{
Esse tecido básico, resultante de muitos planos e ações isolados, pode dar origem a mudanças e modelos que nenhuma pessoa isolada planejou ou criou. Dessa independência de pessoas surge uma ordem sui generis, uma ordem mais irresistivel e mais forte do que a vontade e a razão das pessoas isoladas que a compõem. É essa ordem de impulsos e anelos humanos entrelaçados, essa ordem social, que determina o curso da mudança histórica, e que subjaz ao processo civilizador (ELIAS, 1993, p. 194, grifos do autor).
}

Nesse sentido, os conceitos produzidos pelo autor, convergentes ao entendimento do curso da mudança histórica, dão forma à análise dos manuais para compreender as concepções do que é civilizado em cada tempo, as formas mobilizadas para internalizar os hábitos, os tipos de conteúdos divulgados e quais eram os ensinamentos propostos na literatura sobre boas maneiras. As referidas questões norteiam o estudo, no entanto, não intencionam produzir respostas, haja vista estarem circunscritas pela premissa do caráter inacabado, característico da vigência dos códigos de civilidade, os quais estruturam e organizam os diversos grupos sociais no tempo, conceito que implica "um número elevado de síntese e que 
situa-se além do horizonte do saber e da experiência" (ELIAS, 1998, p. 11). Ressalta-se, portanto, elaborar reflexões sobre o tema, os conteúdos e materialidade dos documentos em questão, de modo a contribuir no entendimento acerca do lugar desses materiais em um processo contínuo de construção de civilidades.

A leitura, como prática disseminadora e formativa, circulava em diversos suportes e funções, durante e após os períodos das guerras, despertando sentidos e sensibilidades para tempo desordenado pelo caos e a destruição. Entre as muitas modalidades e gêneros, os livros de etiqueta e boas maneiras veiculavam prescrições de comportamentos ditos civilizados, importantes num momento marcado por carências e excessos extremos. Uma possível coesão cultural e a reafirmação dos hábitos considerados civilizados diluíam, em termos, a sensação de estar imerso em um mundo no qual a empatia e a cordialidade se invisibilizavam frente aos distúrbios, no entanto, esse tipo de literatura não foi específica do período. Identificados com maior circulação, provavelmente desde o século XVI, esses manuais eram portadores de conjuntos prescritivos para as diversas circunstâncias da vida, tomando como base, nesse período, a vida na sociedade de corte. Segundo a pesquisadora Maria Cecília Barreto Amorim Pilla, em seus estudos a respeito das remodelações promovidas pelo rei francês Francisco I, em Paris, no século XVI:

Esse empreendimento 'civilizatório' trazia em seu bojo também uma crescente preocupação em relação ao refinamento dos costumes, pois se acreditava que as civilidades, sua aprendizagem e prática, influíam nas relações entre as pessoas e seriam ingredientes eficientes para a construção de um mundo mais agradável. Através de guias de conduta, a sociedade europeia do período procurou construir padrões de comportamento capazes de regulamentar a vida das pessoas frente a um período de transição. Não apenas as maneiras de falar e de pensar, as posturas, gestos, mas os comportamentos em geral acompanhando o curso de um processo civilizador (PILLA, 2016, p. 152).

O período abordado por Pilla está, predominantemente, circunscrito a um tempo linear no qual a evolução é sinônimo de melhoria. Era previsto que as sociedades rumassem para condições mais aprazíveis, tanto no âmbito material, quanto espiritual e cultural. O refinamento dos hábitos era um percurso a ser seguido pelos indivíduos, no sentido de dar continuidade a um processo no qual, "toda essa reorganização dos relacionamentos humanos se fez acompanhar de correspondentes mudanças nas maneiras, na estrutura da personalidade do homem, cujo resultado provisório é a nossa forma de conduta e de sentimentos 'civilizados"' (ELIAS, 1993, p. 195). Dessa forma, constituiu-se uma visão sobre o ajuste da conduta humana no qual prevaleceu o princípio que compreende como necessária a preparação dos indivíduos para uma convivência cordial e polida, bem como, para a penetração em círculos sociais mais restritos. E, com esse intuito, eram produzidos subsídios com o potencial de sugerir homogeneidades e padrões, entre os quais, os manuais de etiqueta e boas maneiras.

Desde o século XVI são identificadas relevantes obras que trataram das questões educativas relacionadas aos hábitos, à higiene, ao convívio de uma forma geral. A obra 
De Civilitate morum puerilium de Erasmo de Roterdã, publicada pela primeira vez em 1530, tornou-se um ícone das obras dedicadas aos processos formativos de comportamentos. Organizado em sete capítulos, o livro apresentava prescrições para crianças em diversos tipos de eventos e situações vivenciadas num ambiente citadino, corroborando a ideia de que "desde o começo da mocidade, o indivíduo é treinado no autocontrole e no espírito de previsão dos resultados de seus atos, de que precisa para desempenhar funções adultas" (ELIAS, 1993, p. 202). Como meio de padronização e orientação das crianças para conviverem de forma ordenada e pacífica, o livro consagrou-se como um manual de formação, o qual foi traduzido para muitas línguas e editado inúmeras vezes. Outras obras citadas no manual de civilidade Guia de Boas Maneiras, do autor brasileiro Marcelino de Carvalho (1961), versaram sobre temas afins, por exemplo, Miroir de la jeunesse, de Mathurin Cordier (1559); Galatéo ovrero de costumi, de Giovanni Della Casa (1598); Bienséance et de la Civilité chrétienne, do padre Jean Baptiste de la Salle (1711); Traité de politesse, de Jules Clément (1880), indicando que a produção desse tipo de literatura teve circulação em diversas línguas.

A intensificação da vida urbana e a formação de novas classes nas sociedades europeias demandaram o estabelecimento de parâmetros de comportamento ajustados ao ambiente das cidades e aos seus inúmeros eventos. Os embates pelo controle da circulação do capital favoreceram a emergência da burguesia, classe prioritariamente urbana, a qual almejava ilustração no sentido de se equiparar aos herdeiros da nobreza, portadores de uma identificação familiar tradicional que lhes assegurava espaços e acessos. As publicações que tinham como matéria as prescrições comportamentais que conferiam maior ou menor grau civilizatório eram materiais auxiliares na questão da educação dos corpos, na elaboração das ideias e no refinamento dos modos. Aprender bons modos garantia acessos e ampliava oportunidades na sociedade cortês, por esses motivos se disseminavam os manuais como subsídios para uma configuração na qual, segundo Guereña (2005, p. 30), se "preservava a moralidade e fortalecia a ordem social existente".

No decorrer do século XIX, consagrou-se a produção de um campo literário voltado para as boas maneiras. Os conflitos vivenciados por toda a Europa, a formação dos Estados Nacionais, as grandes revoluções ocorridas até a primeira metade do século, as transferências no monopólio do capital, todas essas questões produziam constantes demandas de reordenação social. A produção de tratados e manuais de boas maneiras se inscrevia nessas demandas e, obteve considerável espaço no consumo de leitura nesse período. Segundo Schwarcz (1997, p. 12), "os manuais possuíam uma estrutura original que privilegiava a leitura rápida e objetiva. A consulta era fácil. E podia-se ir direto ao tema selecionado, sem precisar passar, obrigatoriamente, pelos demais", oferecendo assim, uma leitura instrucional, a qual poderia ser acessada quantas vezes houvesse necessidade ou dúvida.

$\mathrm{Na}$ sociedade brasileira, os manuais foram presentes, possivelmente, desde que os primeiros escritos chegaram com a colonização portuguesa. Um dos mais antigos manuais publicados no Brasil foi o Código do bom-tom ou Regras da civilidade e de bem viver 
no século XIX (1875), ${ }^{1}$ do Cônego José Inácio Roquette, publicado pela primeira vez em Portugal, em 1845. Em seu país de origem, o manual era considerado um importante referencial de educação, uma vez que, o autor contava com as experiências provenientes do convívio com a nobreza e a realeza em Paris e Londres. Com a formação da nobreza em terras brasileiras, a publicação previa atender às necessidades de educação de um reino jovem e em desenvolvimento.

Uma rápida olhada na vasta lista de livros publicados por Roquette revelará que muitos deles destinavam-se, já em seus títulos, a Portugal mas também ao Brasil, onde a voga dos manuais de civilização se iniciou em meados do século XIX. Diante de uma realeza isolada, em meio às demais repúblicas americanas, de um Império escravocrata que dissimulava as marcas dessa instituição e de uma nobreza recém criada, tais guias foram recebidos com o entusiasmo daqueles que tentam apagar as pistas de seu caráter recente e bastante improvisado (SCHWARCZ, 1997, p. 29).

No século XX, já no Brasil republicano, esse tipo de publicação ampliou os espaços de circulação, fazendo parte, inclusive, da educação escolarizada, figurando entre os materiais utilizados na formação de normalistas (CUNHA, 2005), futuras professoras e disseminadoras dos modos apreendidos. Utilizados sob essa perspectiva, aproximavam-se dos manuais produzidos, a partir do século XVI, destinados à formação das crianças, com o intuito de internalizar hábitos de forma precoce como uma garantia de serem informalizados $^{2}$ com maior rapidez. Esse uso dos manuais sinaliza uma permanência no que tange ao objetivo formador, o qual, além de ser direcionado à instrução de crianças, inscrevia-se no campo da educação formal, com intuitos de elevar a potência da disseminação dos conteúdos e estabelecer padrões.

O Brasil, ainda que não tivesse vivido diretamente em seu território os percalços dos conflitos mundiais do início do século XX, compartilhava das tendências editoriais verificadas, principalmente, na Europa e na América do Norte, uma vez que, mantinha relações comerciais e culturais com diversos países das referidas regiões. As transformações políticas e econômicas impulsionaram a constituição de novas formas de ser e conviver

1 Segundo Cunha, esse era o mais famoso manual da época e, em 1900, já havia alcançado a sexta edição, "procurava normatizar os rituais do Brasil Imperial e se tornou leitura obrigatória para aqueles que almejavam ser bem sucedidos na sociedade" (CUNHA, 2005, p. 122). Uma nova edição do manual foi organizada, em 1997, por Lilia Moritz Schwarcz, evidenciando o tema e promovendo uma nova leitura dos comportamentos e convivências.

2 Sobre a utilização do termo, o pesquisador holandês Casparus Adrianus Petrus Maria Cas Wouters desenvolveu a "teoria da informalização dos processos civilizadores", tomando como base os estudos de Norbert Elias e a "sociologia figurativa". Desde a década de 1970 o autor tem dedicado seus esforços de pesquisa ao referido campo, verticalizando suas interlocuções com a obra de Elias e aprofundando as discussões acerca da construção de um autocontrole, das mudanças na contenção das emoções humanas, bem como, os modos de convivência configurados a partir desse processo. O autor é pesquisador da Utrecht University, afiliado à Escola de Amsterdã para Pesquisa em Ciências Sociais e, é membro da Norbert Elias Foundation. Disponível em: http://www.norberteliasfoundation.nl/network/profile.php?profId=5. Acesso em: 20 mai. 2017. 
em sociedade, principalmente no mundo ocidental. No âmbito de relações internacionais constituídas de forma múltipla e variada e, no sentido de compartilhar dos projetos de construção de um futuro promissor, com homens e mulheres preparados para uma convivência pacífica e cordial, as leituras de formação funcionavam como manuais para essa nova fase e, as obras de Maria e D'Ávila se inscreviam nesse perfil. Como aspecto favorável, contava-se ainda com um aquecimento da indústria editorial e do mercado livreiro brasileiro (HALLEWELL, 2005), portanto, havia o estímulo à produções nos mais diversos estilos e classificações. As duas obras utilizadas neste estudo permaneceram significativamente no mercado durante um período prolongado. Rastreamentos virtuais são indicativos que, possivelmente, a primeira edição de Carmen D'Ávila foi produzida em 1934 e a última em $1997^{3}$ e, a primeira da autora Dora Maria foi em 1958 e a última em $1979 .{ }^{4}$ A longevidade das obras sinaliza algum interesse pelas leituras, afinal, considera-se que as editoras não concentrariam os seus investimentos em produtos com poucas possibilidades de retorno financeiro. Em 1958, ano do possível lançamento do manual de Dora Maria, o manual de Carmen D'Ávila estava na $11^{\mathrm{a}}$ edição, com a indicação de que era uma edição revisada e aumentada, com a produção de 89 milheiros. Os dados veiculados no impresso e os projetos editoriais motivados pelo retorno comercial e financeiro, comuns em um mercado livreiro em expansão, são indícios de um possível sucesso de vendagem da publicação de Carmen D'Ávila, a qual permaneceu editada e reeditada por mais de seis décadas.

Os manuais concentram aspectos que os ligam a passados que permanecem ao longo do tempo e atuam na organização das sociedades que, em diferentes conjunturas, demandam por balizas que norteiem a vivência e contribuam na adequação de homens e mulheres às transformações culturais. A sobrevivência desses materiais ao longo do tempo permite problematizar a sua inscrição temporal, no sentido de que, "trata-se aqui de um eixo temporal móvel, cujo ponto de origem é sempre a geração atual e que, por isso, se desloca constantemente" (KOSELLECK, 2014, p. 269). Produzidas a partir das demandas do seu presente, as prescrições mobilizavam elos com passados por meio do uso de referenciais que, teoricamente, tiveram êxito na elaboração das convivências. Dessa forma, tornavam-se legítimas e passíveis de serem continuadas. Ao mesmo passo, o argumento de serem modos exitosos no passado possibilitava uma prospecção, alargando a vigência daquele presente. É possível que esses deslocamentos temporais tenham contribuído para o interesse sobre essas leituras durante um período ampliado, possibilitado por marcos móveis para um presente de maior alcance. E é nesse sentido que o olhar sobre esses modos prescritos e disseminados pela cultura escrita em forma de manuais possibilita depreender aspectos das mudanças ou permanências sociais, uma vez que a dinâmica denominada como civilização institui-se em constante movimento, independente das conjunturas.

\footnotetext{
Disponível em: https://www.estantevirtual.com.br/b/carmen-davila/boas-maneiras/3461541077\&offset=2. Acesso em $1^{\circ}$. abr. 2017.

4 Disponível em: https://www.estantevirtual.com.br/b/dora-maria/aprenda-as-boas-maneiras/13794 $\underline{34549 ? \mathrm{q}=\text { aprenda+boas }+ \text { maneiras }+ \text { dora }+ \text { maria\&offset }=3}$. Acesso em $1^{\circ}$. abr. 2017.
} 
A validade dos manuais de etiqueta e boas maneiras remete não somente ao caráter provisório e incompleto da formação social mas, também, à presença de elementos estruturais sob os quais se constituem as relações sociais. A existência de movimentos de contenção das pulsões já era evidenciada por Elias (1993, p. 191) ao desenvolver as suas "sugestões para uma teoria de processos civilizadores", quando trata das transformações comportamentais e culturais da sociedade de corte, no entanto, a permanência das edições por algumas décadas pode, igualmente, ser relacionada ao ponto em que Koselleck (2014) trata de sistemas que subsistem aos eventos individuais, ou seja, formas de conduta consciente ou inconsciente, as quais condicionam os indivíduos e, por sua vez, criam condições de repetibilidade num processo de compartilhamento, passível de gerar ou não identificação entre os seus contemporâneos. Nesse caso, a questão da repetibilidade se dá em vários níveis, no sentido da grande quantidade de informações que os manuais oferecem. Assim como determinados itens podem ter sua adesão e compartilhamento de maneira amplificada, outros podem definitivamente permanecer no status das leituras que nunca serão feitas. A alta demanda pelo mesmo título permite pensar um grau elevado de identificação com aquele tipo de prescrição e, por conseguinte, um intenso compartilhamento com condições de produção de um "aparelho automático de autocontrole" (ELIAS, 1993, p. 196), o qual tem capacidade de balizar os comportamentos e moldar as condutas de forma autônoma e ordenada.

Os possíveis leitores desse tipo de literatura pertenciam a um grupo social com condições materiais e instrumentais de utilizar tal subsídio para a sua formação. Ainda que, como já foi mencionado, o mercado livreiro brasileiro estivesse em um período de crescimento, não se pode ignorar os níveis de alfabetização, as limitações financeiras das classes trabalhadoras e a própria constituição de uma sensibilidade para o polimento como uma forma de ascensão social. Os manuais delineavam um grupo de interlocutores a partir do tema, dos conteúdos e da materialidade. A partir desses aspectos, será construída a abordagem que se segue.

\section{SOBRE O TEMA, OS CONTEÚdOS E A MATERIALIDADE}

Este livro não se destina à alta sociedade. É um livrinho genuinamente popular, que você deverá ter em casa, guardar em sua gaveta de trabalho ou levá-lo consigo no bolso ou na bolsa, para consultá-lo uma, duas, três ou dez vezes por dia, conforme se tornar necessário, durante suas atribuições no lar ou fora dele.

A vida atual se mecaniza de maneira tão atordoante, confundindo de tal modo homens e coisas, que se ressente a personalidade da deficiência de uma orientação social - base de toda beleza exterior do ser humano.

Pais e professores também se veem arrastados nessa carência de tempo e a geração que se forma vê-se na contingência de sofrer os resultados daquela deficiência, a não ser que busque, pela sua própria vontade, encontrar um guia especializado.

Este será o seu guia, leitor amigo, e, nesta apresentação, formulamos os nossos sinceros votos de um grande, um imenso êxito em sua vida social (MARIA, 1958, p. 7). 
Em sua nota introdutória, a autora Dora Maria faz alusão aos destinatários de sua obra.

Ao primeiro contato com os seus leitores, a autora anuncia suas intenções de fornecer uma leitura utilitária, de fácil acesso e portabilidade e, que contemple as mais diversas situações cotidianas nas quais podem surgir dúvidas ou impasses quanto aos modos e as formas. Ainda que as boas maneiras configurem formas de destacar-se pelo polimento em meio aos grupos sociais em que se circula, a autora enfatiza que não se dirige às classes mais altas e nomeia sua obra de popular. A estratégia discursiva constituiu um meio de estabelecer identificação com um grupo leitor, entretanto, não pode ser considerado como elemento único de delimitação. A elaboração de taxonomias no campo dos textos e das leituras se vincula mais aos usos e menos as classificações, como já havia constatado Roger Chartier (1990), em seu amplo estudo, que resultou na obra História Cultural: entre práticas e representações. A intencionalidade dos autores, mesmo quando explicitada, não define por si os usos feitos de suas obras, o manual pode ter sido pensado como "popular", porém, isso não constitui uma afirmação. O texto de Dora Maria é apresentado como uma alternativa à restrição do tempo para instruir-se e, como uma complementaridade à formação dada no âmbito familiar e escolar. Colocando-se no patamar de uma amiga dos seus leitores/as, a autora disponibilizou conteúdos que buscaram abarcar os diversos espaços e contextos da vivência cotidiana, no sentido de exemplificar os comportamentos adequados a cada situação. Na mesma esteira de constituir-se em um apoio cotidiano, o manual de Carmen D’Ávila é apresentado a partir de outro lugar.

Este livro é um secretário particular, confidente discreto dos pequenos embaraços da nossa vida em sociedade.

A edição que hoje vem a público é a décima primeira, e, como das outras vezes, não me ocorre a quem possa eu oferecer um só dos seus exemplares...

Porque foi precisamente na convivência fidalga de todos quantos me cercam, que aprendi as lições que aqui deixo (D’ÁVILA, 1958, p. 5).

A autora, assim como Maria, anuncia seu texto como um apoio para os eventos cotidianos, entretanto, sinaliza desconhecer qualquer pessoa que necessite desse tipo de apoio. A observação é justificada pela atribuição de seus conhecimentos às convivências entre pessoas que compartilhavam de comportamentos adequados e hábitos polidos, os quais a autora assemelhou ao grupo social dos fidalgos. Há um recorte implícito que delimita os interlocutores dos textos de D'Ávila. Ao declarar sua convivência entre as classes mais altas, a autora localiza o seu lugar social, bem como, o da construção dos seus discursos. Dessa forma, são desenhados contornos diversos para as boas maneiras pensadas por D'Ávila e por Maria. As apresentações de seus manuais, como protocolos de leitura (CHARTIER, 1990), elaboram as primeiras expectativas acerca dos conteúdos e têm o potencial de aproximar um tipo determinado de leitores. Essas delimitações constituem os elos simbólicos que configuram os grupos e afirmam valores compartilhados e aceitos pelos mesmos. Em um sistema no qual Elias (1993) afirma serem necessários densos laços de interdependência, os indivíduos se inscrevem sob um estatuto de formação permanen- 
te que lhes assegure o estabelecimento e a manutenção de espaços e condições. Ainda que direcionadas a grupos diversos, as boas maneiras delineiam homogeneidades, as quais ocorrem em vários níveis e de diferentes formas, pois, se as autoras pensaram seus manuais sob determinadas premissas, para um público específico, a única indicação de como se efetivaram esses projetos é a necessidade de inscrição dos indivíduos nos variados âmbitos de uma sociedade.

A historicidade dos temas de etiqueta e boas maneiras infere sobre um tipo de literatura produzida com fins específicos para atender às demandas de cada período em que teve maior ou menor ênfase. Essas demandas foram circunscritas por eventos de natureza política, econômica, social, cultural ou qualquer necessidade emergente. Instrumentar os indivíduos para novos contextos, ou mesmo, estimular mudanças, faz parte de um movimento contínuo e global que se dá de forma diversa e desigual entre as inúmeras culturas. A elaboração dos discursos das duas autoras dos manuais desse estudo sinalizou que o tema foi difundido e abordado de maneira a contemplar a estratificação social e suas peculiaridades, mas isso não os afasta da perspectiva de serem escritas pensadas na clave da distinção (BOURDIEU, 2007) e da ascensão social, nas quais o referencial e a exemplaridade têm como parâmetro os modos comuns em grupos já estabelecidos, por exemplo, os que circulam em lugares públicos (clubes, teatros), os que têm cargos oficiais ou, até mesmo, a nobreza em sua corte.

A organização dos conteúdos foi construída nos dois manuais considerando esses espaços, situações e exemplos. Os itens que compõem os índices - como são nomeados - permitem vislumbrar as relações no âmbito privado e no público, o comportamento individual e a relação com o outro e com os grupos. Os itens destacados pelas autoras têm pontos comuns, entretanto, priorizam os assuntos conforme a perspectiva sobre a qual foram pensados e o público ao qual desejam estabelecer identificações.

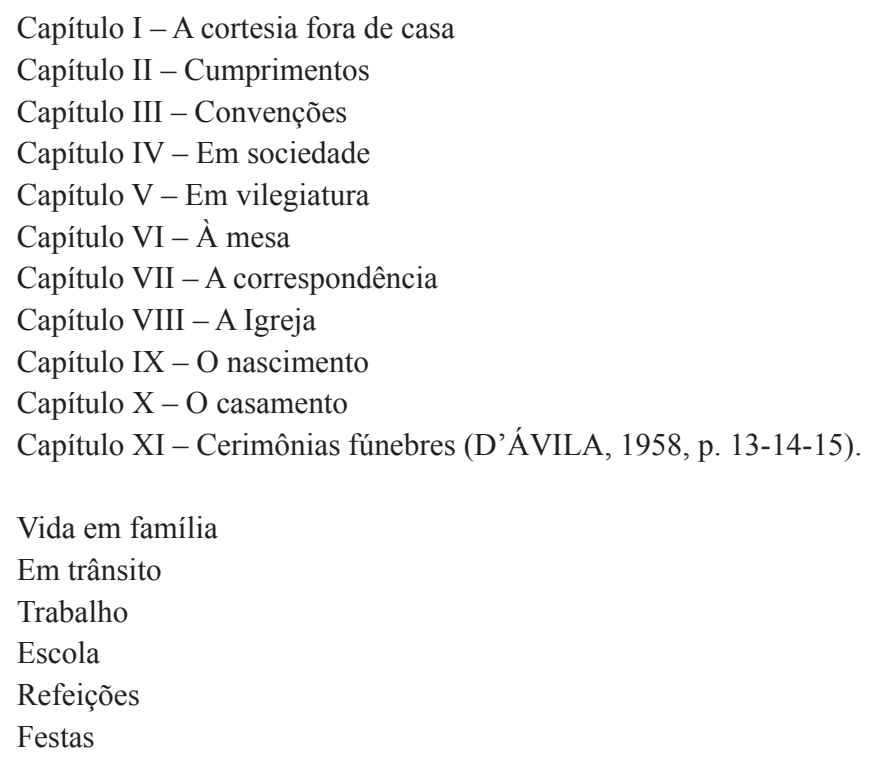




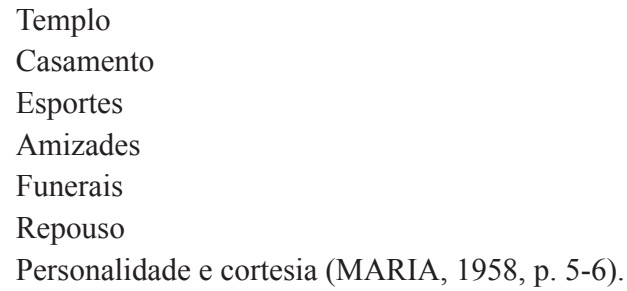

O manual de D'Ávila manteve o foco sobre as situações coletivas e o comportamento em lugares públicos. A proposta formativa foi construída para instrumentalizar os leitores quanto à sua atuação nos diversos espaços de convivência, como maneiras de externar a capacidade de boa sociabilidade e a adaptação aos diversos contextos. Houve uma preocupação com os protocolos da escrita, uma vez que as correspondências constituíam um importante meio de comunicação e divulgação. O manual de Maria acrescentou itens que contemplassem espaços específicos como Trabalho e Escola, sinalizando um olhar sobre as boas maneiras como um processo, o qual se desenvolve no decorrer das atividades formais de educação. $\mathrm{O}$ espaço religioso foi uma abordagem comum aos dois manuais, enfatizando as práticas de fé como uma constante entre diversos grupos e como uma peculiaridade da cultura brasileira, na qual se valorizam consideravelmente as práticas religiosas, assim como, os rituais vinculados às mesmas. Como expressão máxima desses rituais, os dois manuais destacam as prescrições relativas ao casamento. O manual de D'Ávila subdivide o capítulo entre todas as fases possíveis relativas ao importante cerimonial.

O pedido - Como se faz um pedido - Noivado - Primeira visita - Jantar - Noi-
vos órfãos - Participações - Pais separados - Participação de casamento de um
filho ou filha - Presentes oferecidos pelo noivo - Anel de noivado - As alianças
- Flôres - Fotografia - Presentes oferecidos pela noiva - Presentes oferecidos
aos noivos - Exposição de presentes - Ruptura de noivado - O enxoval - Como
se marca um enxoval - Testemunhas - Papeis de casamento - Casamento civil
- Casamento religioso - As demoiselles d'honneur e os garçons d'honneur -
Ornamentação da igreja - O vestuário da noiva - Viúva ou noiva depois dos
quarenta anos - O noivo - Cavalheiros - Senhoras - O cortejo - Entrada na
igreja - Diante do altar - Bênção das alianças - Na sacristia - Cumprimen-
tos - Recepção - Chegada dos convivas - Resumo - Separações e anulações
(D’ÁVILA, 1958, p. 15).

As prescrições de D'Ávila evidenciam uma preocupação com todos os detalhes do evento. $\mathrm{O}$ item não contempla apenas o rito em si, mas todo o percurso até o dia do casamento, inclusive, possibilidades posteriores, por exemplo, a separação. A relação amorosa estabelecida entre duas pessoas figurava entre o repertório de situações sociais passíveis de regras reguladoras e merecedoras de especial atenção por parte da literatura formadora, haja vista a quantidade e a especificidade dos itens que compunham o capítulo $O$ casamento. É possível vislumbrar os sutis recortes de público leitor por meio da organização dos conteúdos, os quais prescrevem os rituais com uma riqueza de quesitos nem sempre possí- 
veis para grupos dispostos a menores investimentos nesse tipo de evento. A autora Maria apresentou uma organização mais sucinta.

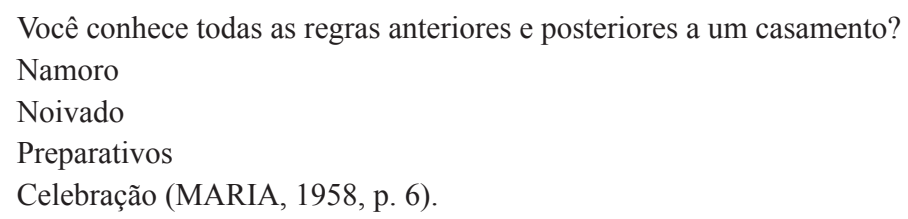

A economia de itens não diminui a importância do rito, entretanto, elabora outra lógica referente a um mesmo processo. A autora não deixou de se referir ao período anterior, tratando do Namoro e Noivado, porém, tratou do processo todo do casamento em dez páginas, ao passo que D’Ávila dedicou 63 páginas ao mesmo assunto. A abordagem permite pensar a valorização dos cerimoniais nos diversos contextos sociais e a perenização das formas como um meio de afirmar as supostas tradições, igualmente, constitutivas de diferenciação entre os grupos. No caso do casamento, instituído e legitimado, tanto como ritual quanto como prática social, no que tange às formas, pode classificar, destacar ou invisibilizar os indivíduos perante a sociedade em que estão inscritos. O compartilhamento das mesmas práticas, ainda que de formas diferentes, aproxima as diferentes estratificações e confere espaços de prestígio dentro de uma perspectiva que viabiliza compartilhar de uma tradição comum e organiza os grupos em um sistema aparentemente ordenado e pacífico.

A convivência entre indivíduos ou classes é mediada por parâmetros ou normas que não são fixas, tampouco estáticas. Cada tempo articula técnicas, invenções, modismos, validados pelos contemporâneos que se utilizam em maior ou menor dimensão. Cabe ressaltar que essa mediação é socialmente construída e individualmente informalizada (WOUTERS, 2007), na medida em que as atitudes deixam de ser alvos de cobrança ou controle externo. Os mais usuais gestos se tornaram matéria de manuais de etiqueta e boas maneiras, justamente por serem práticas não totalmente internalizadas, ou mesmo, relegadas por algum motivo ou contexto específicos.

\footnotetext{
Para cumprimentar na rua, o cavalheiro deve: tirar o chapéu (pela aba, se for de palha, pela copa se for de feltro) sempre com a mão direita; tirar da boca o cigarro quando estiver fumando, inclinar respeitosamente a cabeça e o busto e colocar novamente o chapéu, sem alisar os cabelos (D’ÁVILA, 1958, p. 40-41).

Encontrando amigos ou conhecidos e entabulando conversação, não faça em altas vozes nem dê gargalhadas, pois isto, além de irritar os outros leva-lhes ao par da sua vida, que, de maneira alguma, interessa aqueles que nem o conhecem (MARIA, 1958, p. 22).
}

As mais corriqueiras situações eram conteúdo dos manuais, em um gesto de não permitir o esquecimento sobre os comportamentos do cotidiano. $\mathrm{O}$ gestual e a corporeidade, aparentemente intrínsecos à situação são escritos como lembretes do que já se sabe, mas, 
não se pode esquecer, de forma alguma. A trivialidade das prescrições infere sobre o caráter improvisado e processual da civilização ao qual se referiu Schwarcz (1997) no início do texto, corroborando a teoria de Elias (1993). Cenas que se repetiam inúmeras vezes por dia nos espaços públicos constavam na tessitura dos conteúdos dos manuais, evidenciando a necessidade dos indivíduos de internalizar posturas e condutas já legitimadas, entretanto, deixadas de lado em situações de conflito ou descontrole. Além das situações comuns a qualquer indivíduo, outro ponto abordado se refere aos espaços públicos de entretenimento. Os manuais apresentam a etiqueta para os mais diversos espaços como, bailes, teatros, restaurantes, recepções etc. Segundo D’Ávila (1958, p. 113), “a sala de um teatro num recital de gala é um dos mais belos espetáculos da vida mundana", portanto, considerou a autora, ser um espaço no qual a cortesia deve nortear as relações durante a breve estadia. Nesse sentido, a autora alerta para a postura esperada nesse tipo de ambiente.

\begin{abstract}
A frequente mudança de posições, a tagarelice contínua, etc., tornam, as vezes, muito incômoda a vizinhança de uma senhora na plateia. Durante o espetáculo não se conversa com os vizinhos; as apreciações de desagrado ou entusiasmos devem ser reservadas para os entre-atos (D’ÁVILA, 1958, p. 114).
\end{abstract}

As recomendações enfatizam o comportamento devido tanto ao desconhecimento das condutas, quanto pela inconveniência de não respeitar os demais na plateia. Os conteúdos se desenvolvem pelo exercício contínuo de priorizar o benefício coletivo em detrimento do individual, em uma perspectiva social do processo civilizador, a qual visa ao controle dos ímpetos e a convivência cordial entre os grupos, ainda que diversos em sua procedência e cultura, conforme enfatiza o estudo de Norbert Elias (1993). No manual de Dora Maria, além de eventos de gala, as manifestações culturais também foram contempladas como espaços de convivência que devem ser norteados por alguns padrões, considerados pela autora como pertinentes aos grupos civilizados. Ao passo que Carmen D'Ávila, no capítulo Vilegiatura, abordou os itens $O$ teatro; Equitação; O restaurante; Jantar dançante; $A$ hospedagem, a autora Dora Maria, no capítulo correspondente ao tema, nomeado Festas, tratou de Natal; Carnaval; Festas juninas; Páscoa; Aniversários e Festas em Clubes Embaixadas. O caráter considerado, em maioria, popular das festas selecionadas por Dora Maria, não se distancia da atenção ao que considera de bom tom para os eventos.

Se você deseja brincar o Carnaval junto à família, procure antecipadamente fazer parte de um bom clube, de preferência em seu bairro (para evitar os atropelos da volta), pois um ambiente seleto é o indicado para que não hajam os aborrecimentos comuns das rodas desconhecidas. Se não deseja acompanhar a família, então fique à vontade para escolher o clube de sua preferência (MARIA, 1958, p. 70).

É importante ressaltar, ainda que se trate de perspectivas diversas sobre as civilidades e de autoras com diferentes visões acerca do tema, os tipos de conteúdos selecionados estão circunscritos a uma série de elementos, os quais englobam as escolhas editoriais, o recorte 
de um público-alvo, os objetivos comerciais, entre outros. A construção da lógica prescritiva de cada um dos manuais foi enquadrada pelas expectativas geradas acerca da obra e pelas demandas priorizadas na sua elaboração. Há que se considerar ainda, a década de 1950 como um período em que as indústrias editoriais avançaram sobremaneira na questão da qualidade e produtividade (HALLEWELL, 2005), fator que implica na configuração de equipes que atuavam na elaboração das obras, portanto, os manuais utilizados neste estudo, pertencem a uma dinâmica em que os livros são escritos a muitas mãos. O perfil dos conteúdos apresentados nos dois manuais constitui parte deste contexto.

Uma questão não explícita, porém, recorrente nos dois manuais, é a preocupação em destacar prescrições específicas para as mulheres. Não obstante serem os manuais anunciados para a sociedade, sem especificações, comumente os capítulos dedicaram parágrafos a normas de postura e conduta diferenciadas quanto ao gênero. A estratégia não foi exclusiva das autoras e constava em produções que antecederam suas obras. Esse tipo de categorização esteve visível em manuais produzidos em contextos e tempos diversos. $\mathrm{Na}$ apresentação da reedição da obra de J.I. Roquette, Schwarcz (1997, p. 26) destacou que, "logo no princípio já ficamos sabendo que cabe aos homens polidez e urbanidade e às mulheres um falar suave e um ar reservado. $\mathrm{O}$ homem se distingue por sua fala inteligente e correta; a mulher, por sua atitude modesta e silenciosa". O cônego português enfatizou as diferenças, nas quais homens tinham reconhecimento por suas capacidades técnicas de domínio da linguagem, suas qualidades cognitivas e mulheres por sua capacidade de resignação, sua qualidade "do espírito". Schwarcz evidencia que a perspectiva de universalização das boas maneiras como ícones civilizatórios tinha um contorno nítido sobre o que significava isso para homens e para mulheres. Inspirado nas experiências vivenciadas em Paris, Londres e em seu próprio país junto da alta nobreza, o cônego J.I. Roquette reafirmava valores patriarcais, prescrevendo uma postura social que era esperada das mulheres. É possível que a especificação de comportamentos para homens e para mulheres nos manuais de Maria e D'Ávila contenha resquícios desse passado apresentado por J.I. Roquette, ou tenha inspirado desejos de continuidade dessa concepção de sociedade.

A nota introdutória de D'Ávila (1958) infere que "este livro é um secretário particular, confidente discreto dos pequenos embaraços da nossa vida em sociedade", não selecionando o público para o qual escreve e, incluindo-se, quando se refere à "nossa vida". As formas como a autora exibiu o comportamento considerado de boas maneiras para as mulheres edificou um perfil representado e idealizado no período. Seriam aquelas que dispunham de um considerável poder aquisitivo, o qual lhes permitia compartilhar de determinados espaços e práticas reservados aos estratos mais abastados da sociedade. Às mulheres casadas era sugerido que nunca se apresentassem a um estranho com seu primeiro nome, segundo a recomendação da autora, deveria apresentar-se fazendo referência ao nome do marido: "Eu sou a Sra. Gustavo Sodré" (D’ÁVILA, 1958, p. 63), exemplificou. O modelo familiar do período vinculava a mulher ao marido perante o grupo social de sua circulação, de forma a omitir sua identificação pessoal e constituir-se como um anexo familiar (BASSANEZI, 2007). Corroboram a essa visão as precrições para os cartões de visitas femini- 
nos, nas quais as mulheres deveriam escrever o nome do marido, precedido do pronome de tratamento "senhora", tanto no caso de serem casadas ou viúvas. "Viúxa X é permitido somente nas inscrições de firmas comerciais" (D’ÁVILA, 1958, p. 247), portanto, mesmo após a morte do cônjuge, a representação da tutela permanecia. A construção da necessidade de vincular as mulheres a figuras masculinas, primeiramente ao pai e, na sequência, a um marido, era recorrentemente justificada pela caracterização atemporal das mulheres como seres entregues aos sentimentalismos excessivos. Conforme relata D'Ávila,

O fato é que a mulher sentiu sempre a necessidade de exibir os seus direitos de esposa; tanto que na Inglaterra, houve um tempo em que algumas damas, a fim de protestar contra a união livre e outras decadências, fizeram tatuar na base do dedo anular a aliança de casamento, com a data do noivado e as iniciais do esposo (D’ÁVILA, 1958, p. 323).

A construção da dependência feminina era afirmada por uma ótica, supostamente homogênea. Essa perspectiva se fazia possível a partir de uma construção cultural a qual delineava o percurso de vida dos homens para uma formação profissional, empreendimento na carreira, formação e provimento de uma família e, para as mulheres, a preservação de uma reputação respeitável, a aprendizagem de afazeres domésticos e o casamento, evento destacado com detalhes nos dois manuais. Nesse sentido, o espaço das mulheres era no âmbito doméstico, no qual os eventos ocorridos eram de estrita responsabilidade das mulheres, e estas deveriam dispor de informações e práticas que tornassem o momento agradável para os presentes.

Toda a responsabilidade sobre o brilho de um jantar recai na dona da casa, por isso cabe-lhe um grande esforço, no sentido de que tudo corra admiravelmente, quer conte com grande número de criados, quer disponha de apenas uma ajudante (MARIA, 1961, p. 60).

A ênfase sobre os atributos de uma dona de casa embasava os julgamentos que conferiam sucesso ou fracasso das reuniões sociais realizadas no ambiente familiar. Essas situações eram o cenário dos convívios mais amistosos e descomprometidos, bem como, de oportunidades mais íntimas de se constituir novos laços sociais com objetivos específicos. A participação das mulheres era atrelada à criação das condições físicas para que o evento ocorresse e a figuração familiar, não raro, apresentada como mérito masculino de construir e manter o grupo considerado como primeiro núcleo social. Esses aspectos dos conteúdos diziam respeito à afirmação de valores sociais que mudam de forma lenta e conflituosa. Colocadas como modos a serem seguidos, as prescrições para as mulheres nutriam a ordem patriarcal configurada havia séculos, delimitando os espaços e engendrando meios de minimizar descontentamentos e desencorajar mudanças. O compartilhamento dos modos executados nas altas classes sociais, ainda que com outros recursos, aproximava essa vivência e estabilizava uma ordem reguladora dos lugares sociais de cada grupo. Eram formas de construir igualdades dentro da diferença. 
Encaminhando o último aspecto da análise, no que se refere à materialidade, os dois manuais exprimem as diferenças de suas abordagens nas questões da materialidade e da organização gráfica. O manual de D'Ávila foi publicado pela Editora Civilização Brasileira $^{5}$ e tem 385 páginas. A continuidade de produção de uma obra publicada pela primeira vez no ano de 1934, e, em 1958, na 11 ${ }^{\text {a }}$. edição, produzida em 89 milheiros (segundo informações da contracapa), por uma editora com trabalho já consagrado na década de 1960, sugere êxito na comercialização e uma demanda considerável. O volume do livro, bem como, a apresentação da capa com impressão colorida (Figura 1), em material resistente, são aspectos indiciários de um valor não tão baixo, fator seletivo do público que, possivelmente, adquiriu essa obra. A elevada quantidade de páginas, com poucas ocupadas por imagens, apresenta uma obra dispendiosa nos valores e no tempo a ser dedicado para a sua leitura. As sociabilidades inscritas nos textos das orelhas do manual e na apresentação chamada de Palavras Preambulares, são indicativos da credibilidade da obra, uma vez que, exibir o texto de outra pessoa requer, pelo menos, identificação com a escrita. $\mathrm{O}$ artigo do colunista Guilherme de Almeida. publicado no Diário de São Paulo, de 12 de janeiro de 1949, foi reproduzido na orelha do livro.

Carmen D’Ávila não pontifica friamente: sorri finamente. [...] Exercendo o magistério da elegância e da graça, ela se faz escritora elegante e graciosa. Simultaneamente, por melhor the gravar o conselho, o discurso the esfusia, a cada passo, no epigrama cortês, no remoque sutil, na facecia airosa e levemente acidulada (D’ÁVILA, 1958, orelha).

A anunciada convivência fidalga da autora the conferia a descrição de sua obra em tom elogioso por parte de um jornalista e colunista social. As diversas alusões, principalmente à cultura europeia, legitimaram sua escrita que utilizou muitos exemplos de culturas estrangeiras e priorizou as boas maneiras que estabeleciam diálogos com os modos inspirados na nobreza. Com uma composição gráfica sem grifos, destaques ou cores, a impressão da obra se anunciava como uma leitura densa e sistematizada, eximindo-se de qualquer artifício para chamar a atenção do leitor. A capa, colorida na cor vermelha, enfatiza o título em primeiro plano, Boas maneiras, com letras e cor branca, destacando-se no fundo vermelho. A economia da composição gráfica é compensada pelos textos de apresentação que, como protocolos de leitura, enfatizam no manual o empenho e generosidade da autora, afinal, nas Palavras Preambulares do escritor Cézar Netto "Polir os costumes é exercer uma função de alta benemerência. Para assegurar à trama das sociedades consistência e duração

5 Fundada em 1929, tornou-se o canal mais importante para a moderna literatura brasileira nos anos 1960, além de se dedicar às traduções, tanto dos autores europeus, quanto dos estadunidenses, japoneses e latino-americanos. Segundo Hallewell (2005, p. 539), caracterizava-se por publicar obras que "refletiam as posições da chamada 'esquerda jacobinista", destacando os campos da sociologia, economia e política, e, isso, lhe rendia-lhe o adjetivo de "progressista" a partir da década de 30-40. Até o Golpe Civil Militar de 1964, sua produção editorial seguiu o perfil progressista, inclusive nas publicações direcionadas ao ensino da disciplina de História. Porém, essa postura da Editora, aparentemente se distancia do investimento realizado sobre um manual de boas maneiras, publicado pela primeira vez em 1934 e reeditado até 1997. 
não basta decretar as normas que tutelam o interesse e resguardam a imunidade pessoal". Destaca-se a relevância da obra por sua abrangência de assuntos e legitimidade da abordagem, uma vez que é construída considerando as experiências e conhecimentos adquiridos da autora, fatores que, com as conjunturas que os cercaram, podem ter contribuído para permanecer reeditado e publicado por mais de seis décadas.

Figura 1: Capa do manual de Carmen D’Ávila (1958)

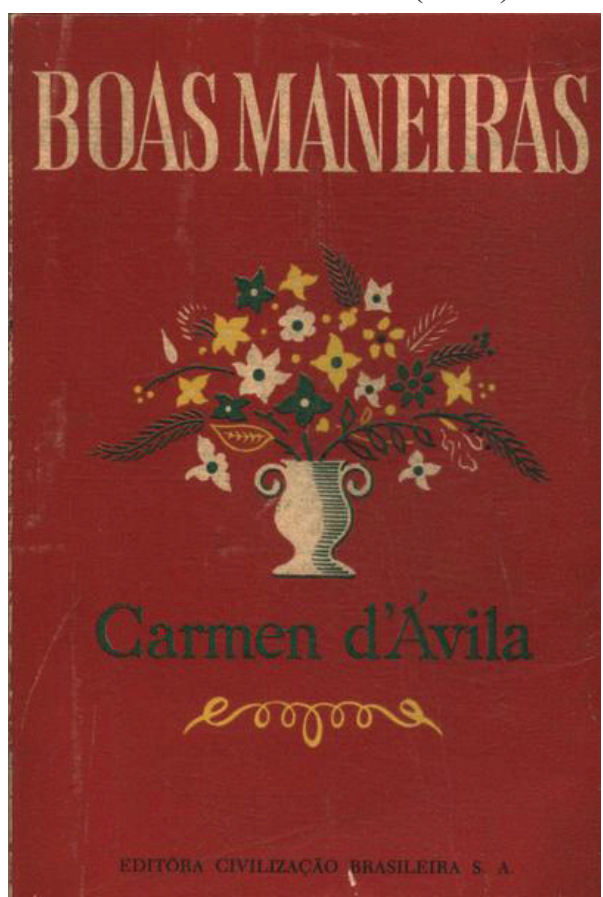

Fonte: Acervo pessoal das autoras.

O manual de Dora Maria foi publicado pela Tecnoprint ${ }^{6}$ e tem 152 páginas. Menos volumoso, foi obra de uma editora dedicada a publicações destinadas às classes com menor poder aquisitivo, comercializadas em livrarias da editora ou em bancas de jornais, com outros produtos para entretenimento. A edição de Aprenda as boas maneiras contava com o recurso da comercialização por meio do correio, o qual efetuava o recebimento dos valores e a entrega. Nas últimas páginas do manual, constavam listagens de títulos publicados pela editora nos mais diversos campos de formação. A Tecnoprint não se dedicava exclu-

6 Fundada na década de 1940, como Editora Gertrum Carneiro, iniciou suas atividades no Rio de Janeiro, local onde permaneceu a sua sede. Como adquiriu a Gráfica Tecnoprint, logo após a sua fundação passou a ser nomeada como Editora Tecnoprint - nomenclatura utilizada no manual de Dora Maria, tornando-se, posteriormente, a Ediouro, uma possível alusão às "Edições de Ouro", selo sob o qual eram nomeadas as livrarias próprias e a publicação de livros técnicos e coleções diversas (HALLEWELL, 2005). A comercialização de suas publicações em livrarias da editora, nas diversas capitais do país, pode ser uma decorrência da dedicação às publicações de entretenimento, com baixo custo, como os caça-palavras e palavras cruzadas sob a marca "Coquetel". 
sivamente a publicações relacionadas à instrução, entretanto, no final do manual de Maria as listagens disponibilizavam diversos tipos de formação pela leitura, inclusive em áreas técnicas, como, encanamento ou eletricidade. Esse manual fez parte de outra lógica de produção e consumo utilizada na década de 1950. Ser publicado e comercializado entre livretos de palavras cruzadas, caça-palavras, manuais para aprender instrumentos ou atividades domésticas, vinculava o manual de Dora Maria a um repertório entendido como popular, pelo fato de ter menor custo e de compra acessível. Assim como o manual de D'Ávila, foi impresso em preto e branco e com pequeno número de ilustrações. Na apresentação da capa (Figura 2), teve um investimento criativo maior, utilizando imagens sugestivas dos conteúdos, estabelecendo uma interlocução diferenciada com os possíveis leitores. A capa não tem cores chamativas, no entanto, tem, em primeiro plano, a imagem de uma mulher, maquiada e com uma blusa ou vestido que lhe deixou o colo à mostra, compondo o espaço com uma cena menor, de noivos sendo conduzidos por uma criança e um conjunto de utensílios de mesa (pratos, copos e talheres).

Figura 2: Capa do manual de Dora Maria (1958)

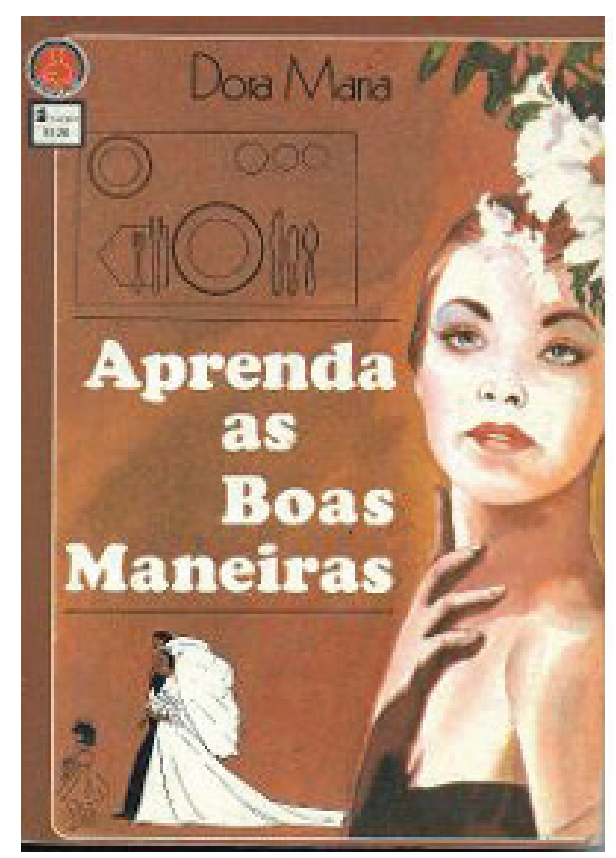

Fonte: Acervo pessoal das autoras.

As estratégias de interlocução utilizadas pelos dois manuais foram diferenciadas no que tange à aparência, ao tamanho, à portabilidade. Nos limites dos documentos, não é possível inferir sobre os valores de mercado dos dois produtos, pois não há qualquer referência aos valores cobrados e, portanto, as interpretações permanecem restritas às informações a respeito das editoras e as formas de comercialização. Publicados no mesmo ano, os 
manuais definiram percursos distintos para atingir públicos diversos, veiculando o mesmo tema, sob perspectivas diferenciadas. A materialidade dos suportes constitui mais um elemento na construção de entendimentos acerca do lugar ocupado por esse tipo de leitura na formação das civilidades. A apresentação, a extensão, a forma e as próprias estratégias de sedução para a leitura configuram diálogos preliminares estabelecidos com os potenciais leitores e, nesse sentido, podem determinar escolhas e atuar sobre as identificações que vão atribuir significados aos textos contidos no interior desses materiais.

\section{CONSIDERAÇões FINAIS}

A variedade dos conteúdos tratados pelas autoras, bem como, a forma de abordagem sinalizada pelo volume dos textos são vestígios da intencionalidade das obras, apresentando em seus índices um repertório de possibilidades quanto aos espaços de sociabilidade e as relações sociais. Um intuito de abarcar as situações inerentes à vida social dos indivíduos, evitando, assim, abrir margem para o inusitado nesse projeto formativo. Acompanhando o movimento de formação contínua dos grupos,

\footnotetext{
Esse "ritmo" nada mais é que uma manifestação do grande número de cadeias entrelaçadas de interdependência, abrangendo todas as funções sociais que os indivíduos têm que desempenhar, e da pressão competitiva que satura essa rede densamente povoada e que afeta, direta ou indiretamente, cada ato isolado da pessoa (ELIAS, 1993, p. 207).
}

A prática solitária da leitura, capaz de produzir sentidos únicos e individuais (CHARTIER, 1990), no caso dos manuais, adquire uma conotação ousada, na qual os sentidos se pretendem coletivos, em uma dinâmica que permita transformar atos vigiados e coagidos em práticas autônomas e racionais (WOUTERS, 2007). A formação proposta nos dois manuais se constrói a partir de lugares diferentes que convergem para uma mesma organização. A ênfase no cotidiano, nas formas mais triviais de convívio, funciona como lembretes de algo que já se sabe, no entanto, precisa ser refinado, melhorado sob a perspectiva de um processo progressivo. A configuração de estruturas de repetição (KOSELLECK, 2014), que sustentem a informalização das práticas, edifica bases consistentes, mais difíceis de serem assoladas pelos percalços das conjunturas. O controle das emoções e racionalização dos atos são contributos de uma sociedade pacífica e ordenada, e funciona como uma espécie de "testemunhos de uma determinada organização das relações humanas, de uma determinada estruturação da sociedade e de um certo tipo de comportamento humano" (ELIAS, 1989, p. 109). Nesse sentido, seja nas prescrições mais banais ou na complexidade da aquisição de conhecimentos práticos, os manuais de civilidade são uma expressão desse projeto educacional contínuo.

As peculiaridades analisadas a partir do tema, dos conteúdos e da materialidade, informam sobre as estratégias específicas dos manuais de Carmen D’Ávila e Dora Maria. A elaboração dessas escritas compõe o discurso vigente no período de sua produção. Em con- 
trapartida, é necessário considerar a longevidade das obras que permaneceram comercializáveis e, sinalizando o interesse de alguns leitores. Corroborando a teoria de Elias (1993), a civilização é um processo inacabado, portanto, além dos espaços formais de educação, as sociedades, engendram outros meios de disseminar formação, e, nessa esteira, figuram os manuais. As considerações elaboradas a partir da discussão sobre o tema, a abordagem de alguns conteúdos e a análise da materialidade permitem evidenciar a continuidade dessa demanda por formação e o potencial de alcance das prescrições, nas quais os exemplos abarcavam certa variedade de contextos. Afinal, este estudo mobilizou como dados empíricos apenas dois títulos referentes à etiqueta e às boas maneiras, em meio a uma gama de publicações a respeito do mesmo tema. Se os Boas maneiras e Aprenda boas maneiras permaneceram interessantes por tantas décadas, é possível que os mais banais modos precisavam - ou ainda precisam - ser lembrados e relembrados. A circulação do tema sinaliza que o processo civilizador está circuncrito pelos mesmos estratos de tempo que atuam sobre a História, os quais, ora iluminam possíveis futuros, ora se resguardam na segurança dos passados e, amalgamados compõem o que se presume como presente. Nesse flanco transita o processo civilizador, com avanços e recuos, amparado na constância do movimento e balizado pela pretensa rigidez das normas e prescrições.

\section{REFERÊNCIAS}

BASSANEZI, C. Virando as páginas, revendo as mulheres: revistas femininas e relações homem mulher. São Paulo: Contexto, 2007.

BOURDIEU, P. A distinção: crítica social do julgamento. São Paulo: Edusp; Porto Alegre, RS: Zouk, 2007.

CARVAlHO, M. Guia de Boas Maneiras. São Paulo: Companhia Editora Nacional, 1961.

CHARTIER, R. A História Cultural: entre práticas e representações. Tradução: Maria Manuela Galhardo. Lisboa: Difel; Rio de Janeiro: Bertrand, 1990.

CUNHA, M. T. S. C. História, Educação e Civilidades: a correspondência como um saber escolar na Escola Normal entre as décadas de 1930 e 1960. Educação, Santa Maria/RS, v. 30, n. 2, p. 121-138, 2005.

D’ÁVILA, C. Boas maneiras. Rio de Janeiro: Civilização Brasileira, 1958.

ELIAS, N. O Processo Civilizador. Volume 2: Formação do Estado e Civilização. Rio de Janeiro: Jorge Zahar Editor, 1993.

. Sobre o tempo. Rio de Janeiro: Jorge Zahar Ed.1998.

. O processo civilizacional. Investigações sociogenéticas e psicogenéticas, $1^{\circ}$. volume. Publicações Dom Quixote: Lisboa, 1989. 
GUEREÑA, J. L. El alfabeto de las buenas maneras. Madrid: Fundación Germán Sánchez Ruiperez, 2005.

HALLEWEL, L. O livro no Brasil. Sua história. São Paulo: EDUSP, 2005.

KOSELLECK, R. Estratos do tempo. Estudos sobre a história. Tradução de Markus Hediger. Rio de Janeiro: Contraponto-PUC/Rio, 2014.

MARIA, D. Aprenda as boas maneiras. Rio de Janeiro: Tecnoprint, 1958.

PILLA, M. C. B. A. A Arte de Receber: distinção e poder à boa mesa. Curitiba: Instituto Memória, 2011.

SARAT, M. Relações entre gerações e processos “civilizadores”. In: GOETTERT, J. D.; SARAT, M. (Orgs.). Tempos e espaços civilizadores: diálogos com Norbert Elias. Dourados, MS: Editora da UFGD, 2009, p. 103-119.

SCHWARCZ, L. M. (Org.). Código do bom-tom. São Paulo: Companhia das Letras, 1997.

WOUTERS, C. A. P. M. C. Informalization: Manners and Emotions since 1890. London: Sage, 2007.

DAdos das aUtoras

\section{MARIA TERESA SANTOS CUNHA}

Doutora em Educação, História e Filosofia pela Universidade de São Paulo. Professora do Departamento de História e dos Programas de Pós-Graduação em História e em Educação da Universidade do Estado de Santa Catarina. Florianópolis/SC - Brasil. mariatsc@gmail. com

\section{MÁRCIA REGINA SANTOS}

Doutoranda em História pelo Programa de Pós-Graduação em História da Universidade do Estado de Santa Catarina. Florianópolis/SC - Brasil.marcia0705@gmail.com

Submetido em: 3-9-2017

Aceito em: 1-11-2017 